\title{
A Preliminary Study on the Cultivating Modes of Chinese Language and Literature Talents in Application-Oriented Universities
}

\author{
Xiaohong Kang \\ Xi'an International University, Xi'an Shaanxi, 710065, China
}

Keywords: Application-oriented universities, Chinese language and literature, Talent cultivating, Mode investigation

\begin{abstract}
With the development of the society, the education methods in China are also constantly improving with the advance of the times. As a great cultural power in the world, China's language and literature accumulation is very rich. However, influenced by the traditional training modes, the mode of cultivation is rather monotonous and lacks application practice in cultivating Chinese language and literature professionals in application-oriented universities. Hence, the paper deviates from the diversified and complex needs of society in cultivating Chinese language and literature talents. In application-oriented universities, only by meeting social demands and closely integrating with the social economy and cultural development needs should the training objectives of Chinese language and literature professionals be established. To adjust the theoretical courses for talent training, and to conduct practical training in combination with the context of the reality is more in line with the cultivation of Chinese language and literature professionals in application-oriented universities. To highlight the educational characteristics of such universities and comprehensively improve the professionalism of students in these universities, enhance their innovative spirit and practical application ability, therefore, this paper explores the cultivating modes of Chinese language and literature talents in application-oriented universities.
\end{abstract}

\section{Introduction}

In recent years, the rapid economic development in China has brought certain changes in the demands of society for personnel with higher education making applicative talents in short supply. In the process of social, economic and cultural development, closely integrating the needs of society and establishing talent training objectives in line with the needs of social development has become a basic concept in all major colleges and universities. As a traditional discipline in colleges and universities, Chinese language and literature is not only designed to enhance the language ability and cultural accomplishment of students in major universities in China. It is also based on the needs of social development and the training of professionals. Although China has gradually made better progress in industrial development, in that process, the cultural accumulation of various enterprises still needs to be constantly upgraded and enriched. Especially so in an increasingly competitive environment. Application-oriented universities should improve their training methods of Chinese language and literature professionals, and should closely integrate the background of contemporary social development, innovate talent cultivation methods and strengthen the practical ability of professionals, and apply the theoretical knowledge learned in class to the problem-solving. And practice and practical ability-oriented talent training mode is more suitable for the development of application-oriented colleges and universities.

\section{Current status of the cultivating of Chinese language and literature talents in application-oriented universities}

Since ancient times, education has been the theoretical basis of China's social development. And for application-oriented universities, strengthening the innovation and application of theoretical 
knowledge is not only a tool for developing and surviving in an increasingly competitive environment but also an important way to train applicative talents. At present, the cultivation of Chinese language and literature talents in application-oriented universities in China mainly focuses on the transmission of theoretical knowledge and does not really rise to the level of practical application. As a result, the development of Chinese language and literature professionals in various application-oriented universities has been stagnating, leading to the shortage of highly qualified personnels engaged in practical work such as public institutions or corporate secretarial and management work in society. The following is the analysis of the problems existing in the training of Chinese language and literature professionals in application-oriented universities, in the following aspects:

(1) The professional personnel training mode is monotonous Influenced by the traditional education mode in China, the training of talents in schools mainly focuses on theoretical knowledge and examinations, but it does not play a good role in the integration of the current social and economic development as well as the rapid development and application of science and technology. As a result, some students lack practical experience when entering the workforce in society. In the process of cultivating Chinese language and literature professionals in application-oriented universities, professional education lacks training in research ability and innovation ability, emphasizing the inheritance of cultural ideas and neglecting practical application, that is, the so-called "strong theoretical research and weak practical application"[1].This "metaphysical" training focusing on the spiritual level while neglecting combining talents training with actual needs of the society, ignoring the practical ability and overall quality of the students will inevitably lead to the conflict between supply and demand of qualified personnel. Such comprehensive talents can skillfully engage practical work in secretarial, publicity and management of enterprises, party and government organs. This is consistent with the diversified and complex needs of the society.

(2) The goal of personnel training is not clear, separated from the needs of society. Colleges and universities have a major responsibility for the training of talents and the future development of society. Any talents come through education in all aspects in school before they serve the society. Therefore, colleges and universities should rationally establish teaching objectives that are in accordance with the actual situation of social development. They should cultivate talents according to the needs of the society instead of the traditional concept of teaching of their schools and only limited to the teaching of knowledge thinking that the goal is to finish teaching the theoretical knowledge needed. With the increasing demand of diversified talents in the society, if the modes of education and training of colleges and universities can not change in time, it will cause the dislocation of talents. And some institutions are too busy blindly chasing the pace of key institutions such as the 985 or 211 and lost the original intention in the training of personnel, which is especially true with application-oriented universities. They need to find out the bright points in their own schools and properly development their personnel training mode according to the needs of social development and the needs of the talents. They can not ridiculously abandon the original intention of running a school.

(3) Chinese language and literature curriculum lacks practical innovation. China's cultural education is under heavy influence of traditional teaching mode. Major colleges and universities all focus on the teaching of theoretical knowledge while for a long time neglecting the importance of knowledge innovation and practical application, which results in the lack of vigor in courses such as Chinese language and literature. And students also lost their interest in learning. For example, in Chinese language and literature courses, teachers focus their efforts on the teaching of literary and language, while not on courses on humanities, innovation, practical and career planning. That is, only to solve the problem of "what", but not the problem of "how" after graduation. In addition, the characteristics of time are also lacking in the course lectures, and the lectures are too old-fashioned, especially lacking in research and inquiry elements. Students are accustomed to rote memorization of the boring theory, and their ability to find and solve problems is poor. Especially, in courses with strong applicative values, blind theoretical knowledge explanation can not effectively bring up students' interest in learning and research. It only hinders the students wide field of vision and bounds 
the breadth and depth of the students' thinking. As a result, the students' scope of knowledge are narrow, and their knowledge are out of touch with practice.

\section{Tips for the cultivating of Chinese language and literature talents in application-oriented universities}

Pay attention to the cultivation of the talents' moral quality and humanistic quality. Chinese language and literature professionals mainly work in the field of management and administration. Therefore, students in Chinese language and literature majors should have correct world outlook, outlook on life and values, as well as good moral character such as diligent and earnest, civilized and honest, unity and cooperative and dedicative to the job and responsibility. Hence the the cultivation of moral quality and humanistic quality is very important. Chinese language and literature professionals must have good-quality self-cultivation, good sense of awareness of responsibility towards the country and themselves. Under the influence of traditional and modern humanistic spirit, they should be able to insist on personal independence and freedom while taking responsibility for the world, leading the cultural development in social development and better integrating into the social development.

Pay attention to the teaching of language, literature, culture, management, publicity and other related knowledge. The training of Chinese language and literature professionals is somewhat different from that of pure technical personnels. The training of Chinese language and literature professionals is mainly for their oral and written expression ability, their learning of basic theory and stylistic knowledge for basic and practical writing, so they will consciously pay attention to and think about the latest research results of the major and related majors and communicate effectively. And they will also have a broad vision and strong learning ability in the fields of Chinese and foreign literature, science and technology, politics and cultural history. This is knowledge structure requirement of the Chinese language and literature[2].This knowledge structure requires students to have a good knowledge of secretarial skills and language, literature, culture, management, advocacy and other related basis.

\section{Measures of the cultivating of Chinese language and literature talents in application-oriented universities}

Innovate in the practical teaching and train diversified personnels. To improve the traditional way of teaching in China, taking the best and abandoning the lesser is now a way of teaching in institutions of higher learning. The traditional way of education in China has its own strengths as well as disadvantages. However, nowadays application-oriented universities can formulate teaching methods reasonably according to the background of social development and the demand of talents. And break the mode of monotonous professional training. Moreover, judging from the current situation of social development, the demand of the society for applicative talents is very urgent. The term applicative talent is comparative to the research talent which is to apply the theoretical knowledge directly to social practice. Therefore, the applicative Chinese language and literature professionals not only need to have a very broad and solid knowledge of Chinese language and literature, but also have strong practical application ability and innovative application ability. In practical work, they should be able to organically integrate the theoretical knowledge education and practical application education. Strengthen the training of Chinese language and literature professionals in verbal communication skills, writing skills and interpersonal coordination skills for work, strengthen the training of professional skills (including the comprehensive training of secretarial skills, etc.) and internship so as to enhance the practical ability of students; Encourage students to take the professional skills certificate test, change the students' traditional teaching methods. And according to the needs of Chinese language and literature professionals, held classical reading, classical poetry recitation and other activities to enhance students' enthusiasm for learning.

Establish clear goals of personnel training. Establish clear goals of personnel training in 
application-oriented universities has a great positive effect on the development of schools, the contribution of talents to the society and the development of society and economy. The establishment of the goal of training qualified personnel in colleges and universities is based on the current status of social development and the current demand for qualified personnel .Improve the traditional professional education objectives and take cultivating the students' overall quality and innovative practical ability as the core, improve the learning and application of professional knowledge of Chinese language and literature majors students in application-oriented universities, and achieve the teaching idea of combining theory with practice. However, as the demand for various kinds of talents in society continues to increase, more and more application-oriented schools, especially some institutions of higher learning mainly based on the training of science and engineering students, have started disciplines of Chinese language and literature to foster the training of secretaries, publicity, management and other professions urgently needed in the society[4].However, due to their lack of experience in running schools and the obscure goals of personnel training, some Chinese language and literature professionals have not gained practical experience when entering society. Therefore, in order to better train Chinese language and literature professionals, it is necessary to set clear goals for running schools and training qualified personnel. Therefore, it is very important that in the future training of talents, the Chinese language and literature professionals should have comprehensive literacy, innovative ability and practical application ability. In the training of Chinese language and literature professionals, all application-oriented universities should formulate clear training objectives in accordance with the actual conditions of social development, strengthen the top-level design, fully consider the needs of diversified and complex talents in different industries and fields, and reform Chinese language and literature professionals training mode.

Optimize the curriculum. The course of personnel training in colleges and universities should be optimized according to the needs of the times and the training mode of applicative talents. Discard the shortcomings in the traditional education mode, enhance the practice of learning and application skills, and reduce the unnecessary parts in theoretical courses. Curriculum optimization should be based on the principle of application and practicality of the course. And the formulation of learning content should be made according to the faculty resources and level of teaching of each college and university. Highlight the characteristics of the training of applicative Chinese language and literature professionals in application-oriented universities. And strengthen the ability to read and write among Chinese language and literature talents. Focus on speech and eloquence, basic writing, media writing, essay writing training in the training courses [5]. Adjust the ratio of theory and practice, and appropriately arrange courses with better application prospect as elective courses; Reform curriculum assessment methods, focusing on examining students' overall quality and ability. Timely adapt to the new economic normal, try to open relevant new curriculum, highlighting the professional characteristics of the curriculum.

\section{Conclusions}

Through the above analysis, we know that in today's rapid socio-economic and cultural development, the demand for applicative talents is also growing. The educational philosophy and training methods of application-oriented universities are also constantly evolving. Chinese language and literature major is regarded as the basic discipline of higher education, but its educational philosophy has been gradually separated from the needs of social development. The connection between the knowledge structure of Chinese language and literature professionals and the needs of society has broken. However, in a highly competitive environment, we can better train more qualified professionals who are more in line with the needs of the society. We should carry out the transformation of the training model and formulate a diversified and practice-oriented training goal to reflect the significance of running an application-oriented university and promote the rapid development and innovation of Chinese language and literature major in social and cultural development. 


\section{References}

[1] Gao Yan. Problems and Countermeasures in the Development of Chinese Language and Literature Specialty in Application-Oriented Universities, Journal of Suihua College. 2014, 12 (12).

[2] Nan Yunfan. Problems and Countermeasures of Chinese Language and Literature Teaching in the new situation, Guangdong Sericulture, 2017 (06).

[3] Dai Chengyuan. Problems and Countermeasures of Local University Chinese Language and Literature Applicative Personnel Training, Journal of Ankang University, 2013 (01).

[4] Jiang Jihua. On Application-Oriented Universities Chinese Language and Literature Professionals Training Mode, Anhui Literature (second half), 2015 (12).

[5] Liao Zhongyuan. Research on the Practice Teaching System Reform of Chinese Language and Literature, Neijiang Science and Technology, 2016 (12). 